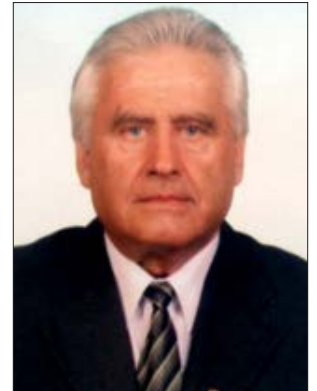

Vladymyr

A. Lebediev

Владимир

Александрович Лебедев

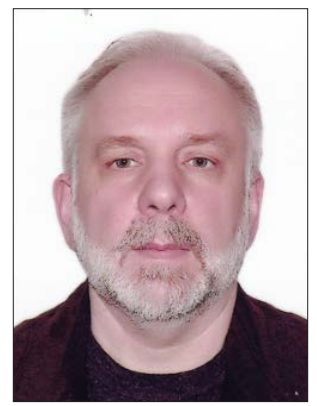

Hennadit

V. Zhuk

Геннадий

Владимирович

Жук

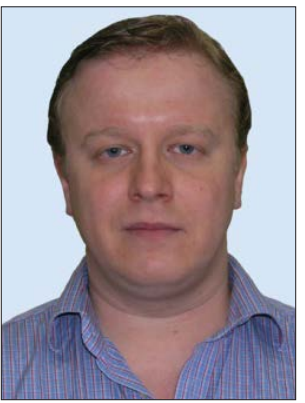

Denis N.

Krazhanovsky

Денис

Миколайович

Кражановский

УДК 621.791 .037

\title{
ADVANCED DEVELOPMENTS FOR WET UNDERWATER MECHANIZED AND AUTOMATIC ARC WELDING
}

\section{НОВЫЕ РАЗРАБОТКИ ДЛЯ ПОДВОДНОЙ МЕХАНИЗИРОВАННОЙ И АВТОМАТИЧЕСКОЙ ДУГОВОЙ СВАРКИ МОКРЫМ СПОСОБОМ}

DOI https:// doi.org/10.15589/smi2019.1(11).5

Vladymyr A. Lebediev

Hennadii V. Zhuk

Denis N. Krazhanovsky
Vladymyr A. Lebediev

Владимир Александрович Лебедев, докт. техн. наук office@paton.kiev.ua ORCID: 0000-0002-0006-3576

Hennadii V. Zhuk

Геннадий Владимирович Жук, директор

dktbpaton@gmail.com

ORCID: 0000-0001-6615-8239

\section{Denis N. Krazhanovsky \\ Денис Миколайович Кражановский \\ kdn17@ukr.net}

\section{The E.O. Paton Electric Welding Institute of the National Academy of Sciences} of Ukraine, Kiev

Институт электросварки имени Е.О. Патона Национальной академии наук Украинь, 2. Киев

Abstract. Underwater arc welding with mechanized or automatic equipment using a melting electrode has recently become more widespread in the repair of ships, in welding of port facilities, repair and creation of product pipelines, etc. Previously, these works were carried out using manual arc welding, localizing the welding site and draining its place of reference. However, to overcome all these time-consuming work, as well as to improve the quality of work, you can apply modern welding equipment and new materials development, effective technical and technological solutions. The first designs of semiautomatic machines for underwater welding of metal, cutting, developed at the PEC them. E.O. Paton, after a fairly large amount of search solutions based on the use of a feed module filled with water. The module houses a hermetic supply unit with a collector DC motor filled with lubricating - insulating fluid. Such designs with a specially developed cored electrode wire are operated for a sufficiently long period of time. The lack of reliability of the collector assembly of a driving electric motor, as well as limited technical and technological capabilities, should be attributed to the drawbacks of the mentioned construction. It may be noted that the existing structures of semi-automatic machines for underwater welding do not solve the frequently encountered problem of ensuring the high-quality weld formation when welding on a vertical plane. Use in new developments of semiautomatic devices for underwater welding of systems of pulsed feed of electrode wire, based on a gearless computerized electric drive with a valve drive motor of a special design, which allows to realize a pulse feed with widely adjustable motion parameters of electrode wire. Pulsed movement of the electrode wire allows controlling the transfer of the electrode metal in the aquatic environment. Purposeful selection of pulses of wire motion allows you to largely control the shape of the welded joint, the penetration, and the structure of the weld metal. The effect of the pulsed feed on the characteristics of the weld metal makes it possible to significantly ensure the high mechanical characteristics of the weld. Modulation of welding modes applied in equipment for underwater welding also allows to improve the characteristics of the welded joint.

Key words: arc welding, aquatic environment, wet method, equipment, application, prospects.

Анотація. Дугове зварювання під водою механізованим або автоматичним обладнанням iз використанням електрода, що плавиться, останнім часом набуває дедалі більшого поширення у процесі ремонту судів, зварювання портових споруд, ремонту та створення продуктопроводів та ін. Раніше ці роботи виконувалися із застосуванням ручного дугового зварювання, локалізації місця зварювання й осушення іiі місця ведення. Однак подолати всі ці трудомісткі роботи, а також підвищити якість робіт можна, застосовуючи 
сучасне зварювальне обладнання та нові розробки матеріалів, ефективні техніко-технологічні рішення. Перші конструкції напівавтоматів для підводного зварювання, різання металів, розроблені в IE3 ім. Є.О. Патона, після досить великого обсягу пошукових рішень базується на застосуванні модуля, що подає, заповненого водою. У модулі розміщується герметичний вузол, що подає, з колекторним електродвигуном постійного струму, заповнений мастильно-ізолюючою рідиною. Такі конструкції зі спеціально розробленим порошковим електродним дротом експлуатуються протягом тривалого часу. До числа недоліків згаданої конструкції варто зарахувати недостатню надійність колекторного вузла приводного електродвигуна, а також обмежені технікотехнологічні можливості. Можна зазначити, що наявні конструкції напівавтоматів для підводного зварювання не вирішують таку поширену задачу забезпечення якісного формування швів у процесі зварювання на вертикальній площині. Застосування в нових розробках напівавтоматів для підводного зварювання систем імпульсної подачі електродного дроту, що базуються на безредукторному комп'ютеризованому електроприводі з вентильним приводним електродвигуном спеціальної розробки, який дає змогу реалізувати імпульсну подачу з регульованими в широких межах параметрами руху електродного дроту. Імпульсний рух електродного дроту дає змогу здійснити управління перенесенням електродного металу у водному середовищі. Цілеспрямований вибір імпульсів руху дроту дозволяє значною мірою керувати формою зварного з'єднання, проплавлением, а також структурою металу шва. Вплив імпульсної подачі на характеристики металу зварного з'єднання дозволяє значною мірою забезпечити високі механічні характеристики шва. Модуляція режимів зварювання, застосована в обладнанні для підводного зварювання, також дозволяє поліпшити характеристики зварного з’єднання.

Ключові слова: абразивні круги, різальна поверхня, абразивний рельєф, шліфування, параметри рельєфу, відносна опорна довжина, відстань між зернами.

\section{References}

[1] Paton B.Ye., Lebedev V.A., Zhuk G.V. (2017). Achievements and prospects for the development of mechanized and automatic equipment for underwater arc welding with a wet method. Underwater Technology, 6, 28-36.

[2] Paton V.Ye., Smolyarko V.B., Bel’for M.G., Pichak V.G. and others. (1969). USSR author's certificate No. 256914. Moskow.

[3] Paton V.Ye., Smolyarko V.B., Bel'for M.G., Pichak V.G. and others. (1973). USSR author's certificate No. 282327. Moskow.

[4] Paton V.Ye., Smolyarko V.B., Bel'for M.G., Pichak V.G. and others. (1975). USSR author's certificate No. 492131. Moskow.

[5] Levchenko A.M., Parshin S.G., Antipov I.S. (2018). Domestic technology, welding complex and flux cored wire for mechanized underwater welding and cutting by the wet method. The world of welding, 1, 18-20.

[6] Kononenko V.YA., Rybchenkov A.G. (1994). Experience of wet mechanized welding with self-shielded flux-cored wires when repairing gas and oil pipelines under water. Automatic welding, 9-10, 29-32.

[7] Kononenko V.YA. (2005). The technology of wet mechanized welding during the construction of "Prirazlomnaya" OIFP. Automatic welding, 9, 37-39.

[8] Savich I.M., Rybchenkov A.G., Pan’kov V.I., Ignatushenko A.A., Paton V.Ye., Smolyarko V.B., Bel’for M.G., Pichak V.G. (1976). USSR author's certificate No. 498131 Moskow.

[9] Lebedev, V. (2016). Unique automatic arc for deep underwater welding wet process under hard limited. Shipping, 2, 62-64.

[10] Lebedev V.A., Gulyy M.V. (2014). High-speed valve electric drive for equipment of mechanized arc welding. Mechatronics. Automatio. Management, 6, 47-51.

[11] Lebedev, V.A., Gedrovich A.I., Borodina K.V. (2013). Electric arc fusion welding of metals of small thickness. Collection of theses of poster presentations of the International Conference "Welding and related technologies - present and future”, 80-81.

Постановка проблемы. Дуговая механизированная и автоматическая сварка с применением плавящегося электрода - распространённый способ качественного производительного и экономически выгодного неразъемного соединения и восстановления различных конструкций деталей и узлов машин и механизмов.

Дуговая сварка в водной среде механизированными или автоматическими системами и оборудованием - один из видов сварки, который находит всё большее распространение в различных сферах дея- тельности человека, с присущими ей проблемами и различными решениями в технической и технологической областях, а также выборе электродных материалов [1].

Укажем, что среди способов сварки под водой распространение получила ручная дуговая мокрая сварка с использованием специальных электродов, а также способ, когда место проведения работ локализуют специальными устройствами (кессонами) с откачиванием воды с места сварки. В последнем случае используется и ручная, и механизированная 
сварка с применением обычных электродных материалов.

Заметим, что мокрая ручная дуговая сварка малопроизводительна и зачастую не обеспечивает нужного качества выполненных работ. Сварка под водой в кессоне весьма затратна и ограничена в применении.

Анализ последних исследований и публикаций. В ИЭС им. Е.О. Патона НАН Украины разработан способ механизированной мокрой подводной сварки с применением погружных устройств подачи электродной проволоки. Для реализации этого способа сварки разработан ряд технических средств - полуавтоматов различных конструкций, на часть из которых получены авторские свидетельства [2; 3; 4]. Выполнена разработка специальных порошковых электродных проволок и технологических приёмов их применения.

Разработанная в институте электросварки им. Е.О. Патона порошковая проволока марки ППС AH1 (диаметр 1,2-2,0 мм) позволяет обеспечить стабильное горение дуги и получение (на низкоуглеродистых и низколегированных конструкционных сталях) сварных соединений, равнопрочных основному металлу. Проволока практически не имеет аналогов и до настоящего времени является основным электродным материалом для полуавтоматов и автоматов, которые используются для мокрой подводной сварки.

Среди предложенных конструкций погружных устройств можно выделить:

- с поддувом воздуха в погружной бокс и применением специальных накопительных камер с воздухом;

- с размещением подающего узла в изолирующесмазывающей жидкости, а всей системы подачи - в водной среде;

- с размещением всего полуавтомата, включая источник сварочного тока, в погружном агрегате.

На основе вышеуказанных предложений в ИЭС им. Е.О. Патона был разработан ряд полуавтоматов, в том числе и тех, которые выпускались серийно или небольшими партиями. В их числе наибольшее распространение получили полуавтоматы А-1660, А-1450, ПШ-141 и ПШ-156.

Отметим, что, согласно работе [5], в настоящее время в РФ появились полуавтоматы для дуговой сварки мокрым способом, которые практически повторяют разработки ИЭС им. Е.О. Патона 70-х гг. прошлого века.

За рубежом, насколько нам известно, механизированная и автоматическая сварка под водой мокрым способом практически не применяется. Исключение представляет КНР, где на основе договорных отношений с ИЭС им. Е.О. Патона развиваются техника и технология механизированной сварки под водой мокрым способом.

Механизированная сварка в водной среде с применением порошковых электродных проволок нашла достаточно широкое применение, примеры чего изложено в технической литературе [6;7].
В процессе развития этого способа сварки были предложены интересные и весьма полезные области его применения с обеспечением соответствующих технических средств для реализации механизированной и механизированной сварки мокрым способом. Среди них, например, следующие:

- сварка подводной части судов и кораблей на плаву (формирование корпуса) [8];

специализированное механизированное устройство для сварки под водой труб;

- автоматизированная сварка для герметизации составных труб, в том числе на большой глубине на нефтегазодобывающих объектах и при создании комплексов с тепловыми насосами [9];

- сварка и резка при проведении аварийно-спасательных работ в водной среде;

- автоматизированная сварка на больших глубинах с применением координатно-программируемых систем на основе компьютеризированных средств управления и регулирования;

- использование механизированного и автоматического оборудования для утилизационной резки под водой, в том числе и при закрытии использованных нефтяных и газовых скважин.

Всё это оборудование прошло опытно-промышленную проверку, а некоторые из систем используются на промышленных объектах. Часть разработок нуждается в совершенствовании.

Так, например, автомат для приварки заглушек внутри труб, разработанный в ИЭС им. Е.О. Патона, успешно работает на глубинах 230 м.

Выделение не решенных ранее частей общей проблемы. Проблема с применением механизированных и автоматизированных технологий дуговых способов подводной сварки мокрым способом и оборудования для них действительно существует и в настоящее время. Однако ранее решались лишь отдельные конкретные задачи, результаты которых в той или иной степени удовлетворяли производителей. Но, как известно, универсальных решений в технико-технологических системах пока не существует, поэтому важным представляется поиск таких решений данной проблемы, которые бы в целом наиболее полно отвечали поставленным требованиям.

Цель исследования - изучение и анализ воздействия на сварочный процесс новых систем подачи электродной проволоки в оборудовании для высокоэффективной подводной сварки мокрым способом.

Основной материал (результаты). Одной из существенных проблем для погружных узлов системы подачи электродной проволоки механизированного оборудования и систем сварочного перемещения автоматического оборудования для мокрой подводной сварки является надёжность работы приводных электродвигателей постоянного тока с коллекторно-щёточным узлом. В разработках ИЭС им. Е.О. Патона эта проблема решена с применением бесколлекторных электродвигателей - шаговых промышленного производства и специ- 
альных вентильных электродвигателей, использование которых с компьютеризованным управлением и регулированием даёт дополнительные преимущества [10]:

- малые габариты, массу и инерционность, в том числе из-за отсутствия необходимости применения механических редукторов (подающий ролик непосредственно на валу электродвигателя);

- возможность программирования движения электродной проволоки с достаточно высокой частотой отработки сигнала задания или координатного перемещения сварочного инструмента на плоскости или в пространстве.

Следует обратить особое внимание на конструктивы, в которых размещаются узлы погружного блока. В последних конструкциях полуавтоматов для подводной сварки мокрым способом электродвигатель заключен в оболочку из нержавеющей стали с компенсатором давления, а система подающих роликов, выполненная из специальных сталей, защищена от обычной коррозии и электроэррозии специальными средствами. Общий корпус сформирован из пластика, который обычно применяется при строительстве корпусов яхт и других маломерных судов. Одна из последних разработок полуавтомата в прочном пластиковом корпусе безредукторным приводом на основе высокомоментного шагового электродвигателя представлена на рис. 1. Такие полуавтоматы могут эксплуатироваться в пресной и солёной воде на глубинах до 40 м, т.е. тех глубинах, где могут работать водолазысварщики. При этом, кроме сварки, применяя специальные электродные проволоки, можно вести эффективную резку металла.

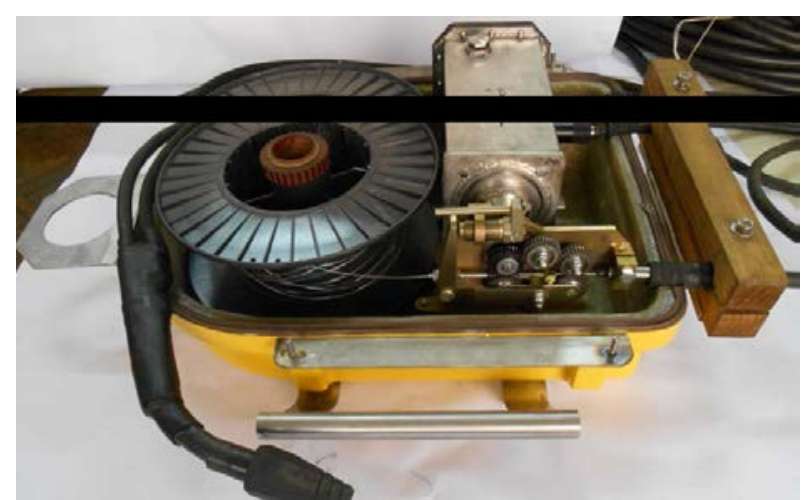

Рис. 1. Полуавтомат последнего поколения (с открытой крышкой) для подводной сварки мокрым способом

В технике и технологии дуговой сварки основным направлением совершенствования в настоящее время является использование импульсных алгоритмов функционирования основных активных систем оборудования. В частности, широко используются инверторные источники с импульсным формированием выходных параметров, в том числе и синергетические.

В последнее время получают развитие способы сварки с модуляцией режимов и выбранными (частично на основе теоретических изысканий с решением задачи управления формированием и кристаллизацией металла шва, частично на основе экспериментальных исследований) частотой и скважностью модулируемых параметров. Такая технология, например, оказывается применимой при подводной дуговой сварке мокрым способом при выполнении вертикальных соединений, выполнение которых представляет определённую сложность, как по фор-

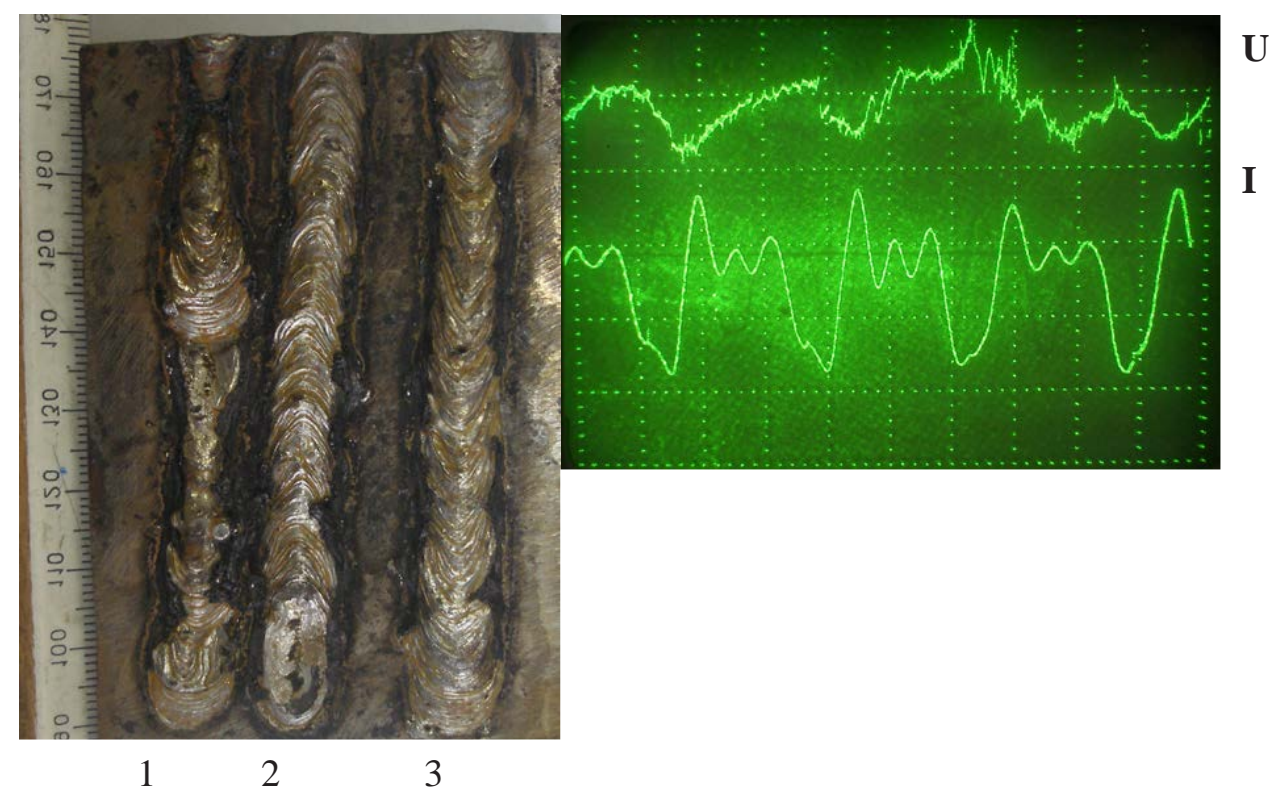

Рис. 2. Наплавленные на вертикальную плоскость под водой валики и осциллограммы напряжения U и тока I при наплавке с модуляцией скорости подачи проволоки: 1- наплавка без модуляции; 2, 3 - валики с модуляцией с разными направлениями ведения процесса 
мированию шва, так и по качеству металла. На рис. 2 показан пример выполнения наплавки конструкционных сталей в водной среде на вертикальной плоскости порошковой электродной проволокой с параметрами: ток - 170-180 А; напряжение - 26-27 В. Модулируется скорость подачи со временами: импульс - 0,6 С и пауза - 0,4 С. Процесс осуществляется механизмом подачи с любыми типами приводных электродвигателей, как коллекторных, так и бесколлекторных, включая шаговые и вентильные с частотами управления модуляцией 0,2-2,0 Гц.

Применение процесса с модуляцией скорости подачи электродной проволоки позволяет в определённой степени решить задачу сварки на вертикальной плоскости с получением сформированных валиков. Такой процесс, как показывают металлографические исследования, практически не оказывает существенного влияния на структуру металла шва, полученного в водной среде. Это, по нашему мнению, является следствием увеличенной скорости кристаллизации наплавленного металла в водной среде в сравнении со сваркой в атмосферных условиях.

Исследование процесса подводной сварки мокрым способом с применением источников сварочного тока инверторного типа, имеющих возможность генерировать импульсы тока с управляемыми параметрами, заметных эффектов, насколько нам известно, не дали, в частности, по изменению структуры металла шва или валика. Мы считаем, что это обстоятельство можно объяснить особыми скоростными условиями кристаллизации металла шва.

В последнее время, опираясь на исследования в области систем подачи электродной проволоки, а также последних разработок в области электротехники и компьютеризованного управления, рассматриваемых как комплектные мехатронные системы, разрабатывается оборудование для импульсной по- дачи по определённой программе электрода в полуавтоматах и автоматах для дуговой сварки.

Для механизированной и автоматической сварки разработан и используется безредукторный электропривод на основе серийно выпускаемых шаговых и специально разработанных вентильных электродвигателей с компьютеризованной системой управления, позволяющей реализовать практически любой алгоритм движения электродной проволоки. При этом вентильный электропривод последних разработок обеспечивает регулируемую по частоте, скважности и амплитуде импульсную подачу электродной проволоки с максимальными частотами 50-60 Гц.

Указанный электропривод исследовался в составе автоматического и механизированного оборудования при сварке - наплавке в водной среде мокрым способом.

Представляет особый интерес получение вертикальных и горизонтальных сварных швов на вертикальной плоскости с достаточными характеристиками по формированию и качеству наплавленного металла. Применение импульсной подачи электродной проволоки с эффективно выбранными параметрами позволяет решить эту задачу.

При импульсной подаче электродной проволоки с рационально выбранными параметрами реализуется управляемый перенос электродного металла по принципу: каждому импульсу подачи соответствует перенос капли расплавленного металла определённого размера. Ускорение, которое при импульсном движении придаётся капле, способствует точному транспортированию капли в расплавленную ванну, что весьма эффективно при ведении процесса на вертикальной плоскости. Особенности переноса электродного металла при подводной сварке мокрым способом с применением импульсной подачи требуют отдельного рассмотрения.

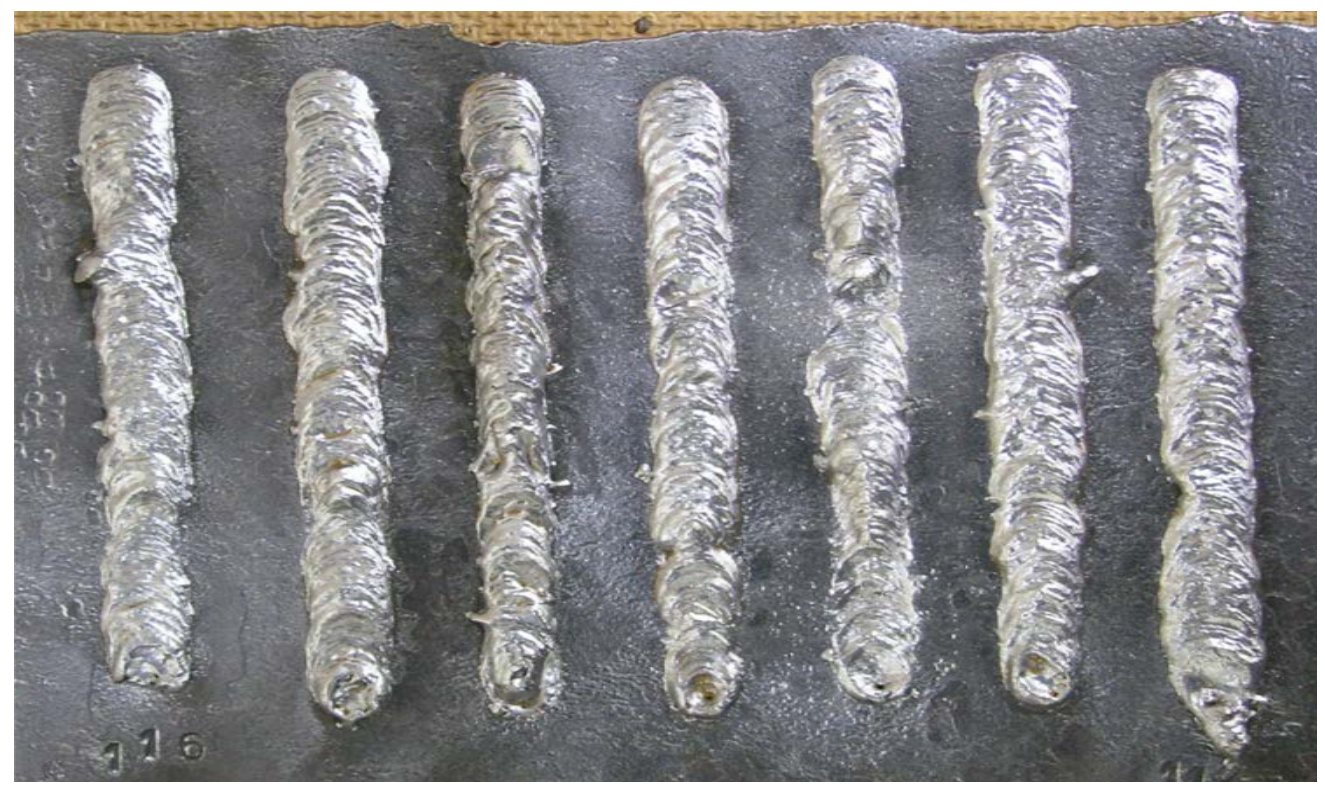

Рис. 3. Валики, наплавленные в водной среде, с применением импульсной подачи электродной с различными характеристиками - частота, амплитуда, скважность 

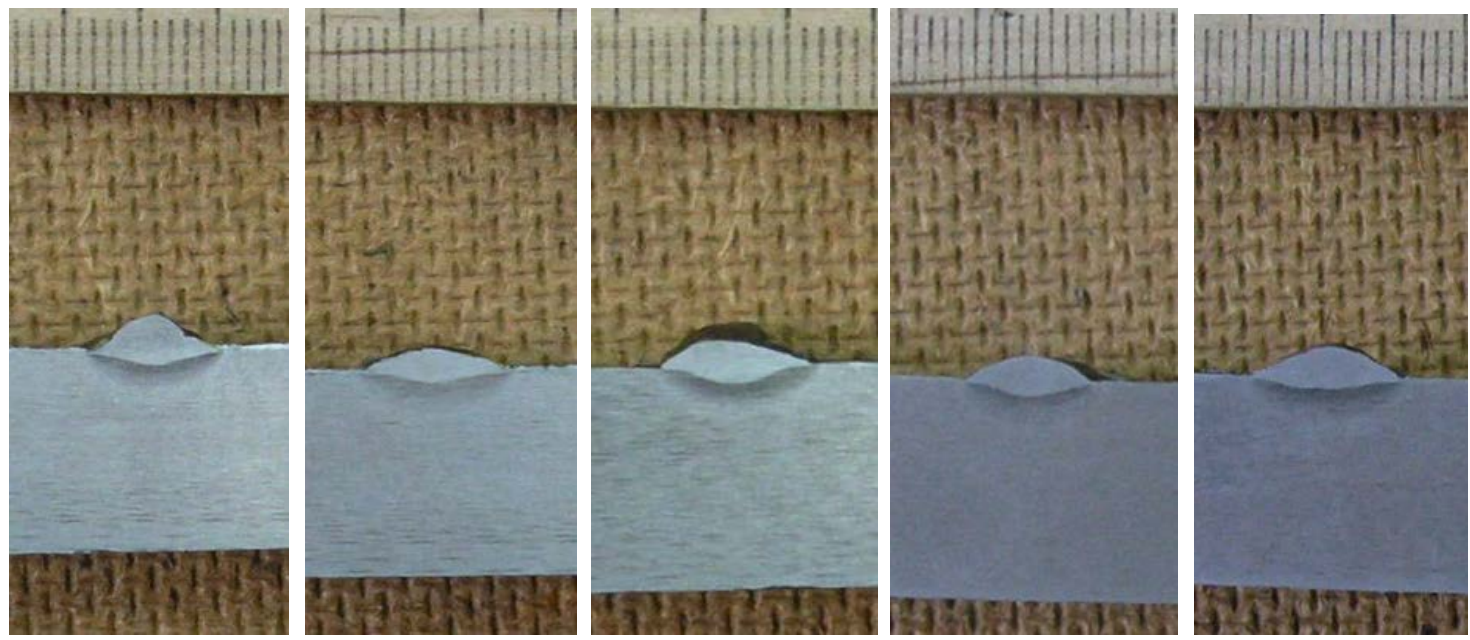

Рис. 4. Микрошлифы валиков, наплавленных с использование управляемых импульсов подачи электродной проволоки

На рис. 3 представлены образцы валиков, наплавленных в водной среде с применением импульсной подачи проволоки с разными характеристиками импульсного движения, но с практически одинаковыми значениями тока, напряжения и скорости ведения процесса. Ток и напряжение дугового процесса 160 170 А и 26-28 В соответственно. Скорость ведения наплавки $-10-12 \mathrm{M} /$ ч.

Можно отметить, что формирование валиков существенно более равномерно наполнено, имеет более регулярный характер. Важной является возможность достаточно интенсивного влияния на параметры валиков: ширину, усиление, глубину проплавления. Характерные микрошлифы некоторых валиков, представленных на рис. 3 , даны на рис. 4.

Необходимо отметить, что тенденции изменения геометрических размеров наплавленных валиков соответствуют тем, которые получены при наплавке в обычных условиях, хотя и менее выражены, что в общем объясняется существенно более высокой скоростью охлаждения жидкой ванны.

Особое внимание уделено качественному анализу металла, наплавленного в водной среде, который проводился на основании исследований микрошлифов поперечных сечений валиков, прочностных (механических) характеристик, состава металла валика и околошовной зоны. Практически по всем параметрам наплавленные с импульсной подачей электродной проволоки превосходят валики, полученные при использовании конвенциальной подачи с тенденциями улучшения характерными с процессами, получаемыми на открытых пространствах при сварке-наплавке с импульсной подачей порошковой электродной проволоки. Однако есть и отличия. Так, например, объёмная доля неметаллических включений в металле наплавленного валика уменьшается лишь после увеличения частоты импульсов подачи, что можно видеть на графике рис. 5, полученном при экспериментальных исследованиях.

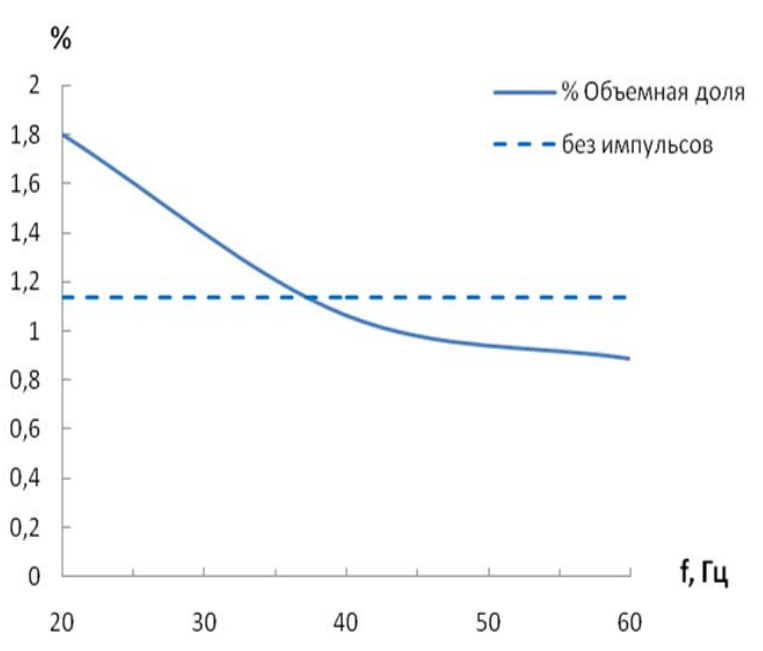

Рис. 5. Сравнительные графики наличия неметаллических включений в металле валиков при наплавке с разными способами подачи электродной проволоки

Это опять, как нам представляется, связано с особенностями характеристик кристаллизации металла шва и околошовной зоны в водной среде.

Некоторое улучшение механических свойств швов, полученных при сравнительных исследованиях сварки с применением конвенциальной и импульсной подачи электродной проволоки с управляемыми параметрами, демонстрируют графики, представленные на рис. 6.

Эти результаты косвенно подтверждают тот факт, что в металле швов или наплавленных в водной среде валиков при использовании импульсной подачи электродной проволоки происходит изменение кристаллической структуры, связанной с некоторой дезориентацией кристаллитов. Этот процесс менее интенсивен, чем это происходит при обычных условиях, что, как уже отмечалось, связано с особыми условиями охлаждения жидкой ванны в воде.

Следует констатировать, что большинство положительных эффектов от импульсной подачи электро- 


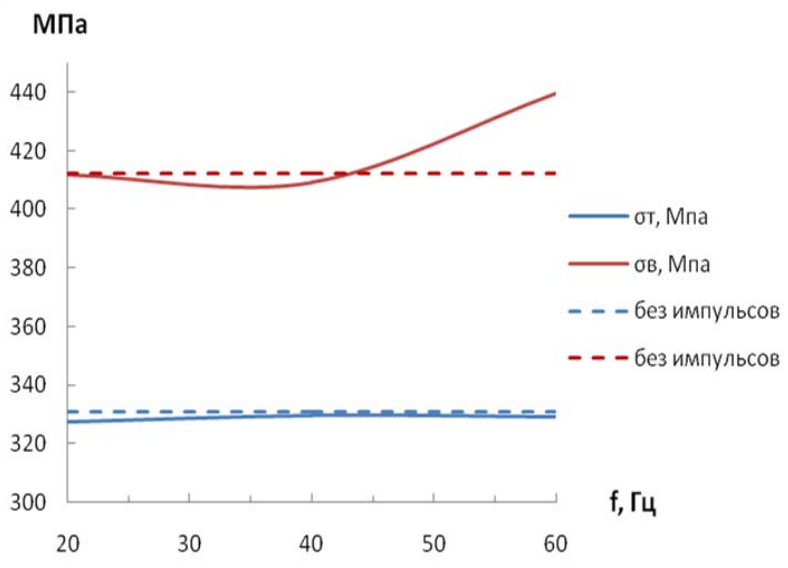

Рис. 6. Зависимости между пределами текучести и временного сопротивления

дной проволоки заметно проявляется при определенном увеличении частоты импульсного движения.

Хорошо известно [11], что качественная сварка с минимизаций деформаций различного типа возможна в случае обеспечения минимальных тепловых вложений в реализацию процесса. Сварка с импульсной подачей электродной проволоки характеризуется пониженными энергозатратами, что в сочетании с интенсивным охлаждением обеспечивает малые деформации свариваемой конструкции, в частности из тонколистовых материалов.

Способы сварки с импульсной подачей электродной проволоки постоянно совершенствуются и развиваются. Часть из них, по нашим убеждениям, основанным на опыте исследовании разработки таких систем, с успехом может быть применима для реализации высокоэффективной сварки в водной среде конструкций с разным пространственным положением.

К числу перспективных способов сварки с импульсной подачей электродной проволоки, применимых в водной среде, следует отнести:

- совместное применение импульсной подачи и модуляции режимов (ток и напряжение сварки как с синхронизацией, так и без синхронизации воздействий);

- использование нового способа сварки с дозированной подачей электродной проволоки;

- синхронизированное по определённому алгоритму импульсное воздействие импульсной подачи электродной проволоки и импульсного воздействия источника сварочного тока.
Обсуждение полученных результатов. Новые способы сварки с применением разработок новых технических средств позволяют в значительной степени улучшить как результаты дугового процесса, так и обеспечить новое качество оборудования - снизить его массогабаритные характеристики и повысить его надежность, что очень важно для аппаратуры подводной сварки. Каждый из указанных новых способов подводной сварки с применением регулируемой импульсной подачи электродной проволоки может решить определённый комплекс задач при ведении процесса подводной сварки мокрым способом, при этом в большинстве способов может быть применён практически любой тип источника сварочного тока, в том числе самый простой по конструкции и возможностям.

Следует отметить, что электроприводы с компьютеризованными вентильными и шаговыми электроприводами применяются для оснащения систем сварочного и установочного перемещения в автоматизированном оборудовании для подводной сварки мокрым способом.

\section{ВЫВОДЫ}

1. К настоящему времени разработано несколько разных конструкций полуавтоматов для подводной сварки порошковыми самозащитными электродной проволоки мокрым способом, но наибольшее распространение как общего назначения, так и для решения специфических задач получило оборудование с изолированным подающим узлом, полость которого заполнена изолирующе-смазывающей жидкостью.

2. Полуавтоматы и автоматы для подводной сварки постоянно совершенствуются, а основным направлением их совершенствования является применение систем подачи электродной проволоки с управляемыми импульсными параметрами движения, рациональный выбор которых обеспечивает возможной высокоэффективной сварки в нижнем и вертикальном положениях с возможностью регулирования геометрических размеров швов и валиков, получения соединения с улучшенными механическими характеристиками.

3. Сложность применения импульсных технологий при сварке в водной среде мокрым способом как за счёт импульсных алгоритмов функционирования источников сварочного тока, так и вследствие импульсной подачи электродной проволоки заключается в высокой скорости охлаждения сварочной ванны, которая существенно превосходит скорость в обычных условиях.

\section{Список литературы:}

[1] Патон Б.Е., Лебедев В.А., Жук Г.В. Достижения и перспективы разработки механизированного и автоматического оборудования для дуговой подводной сварки мокрым способом. Підводні технології. 2017. № 6. C. 28-36.

[2] Патон В.Е., Смолярко В.Б., Бельфор М.Г., Пичак В.Г. и др. Авторское свидетельство СССР 256914. Москва, 1969.

[3] Патон В.Е., Смолярко В.Б., Бельфор М.Г., Пичак В.Г. и др. Авторское свидетельство СССР 382327. Москва, 1973. 
[4] Патон В.Е., Смолярко В.Б., Бельфор М.Г., Пичак В.Г. и др. (1975). Авторское свидетельство СССР 492131. Москва, 1975.

[5] Левченко А.М., Паршин С.Г., Антипов И.С. (2018). Отечественная технология, сварочный комплекс и порошковая проволока для механизированной подводной сварки и резки мокрым способом. Мир сварки. 2018. № 1. C. 18-20.

[6] Кононенко В.Я., Рыбченков А.Г. Опыт мокрой механизированной сварки самозащитными порошковыми проволоками при ремонте под водой газо- и нефтепроводов. Автоматическая сварка. 1994. № 9-10. С. 29 -32.

[7] Кононенко В.Я. Технология мокрой механизированной сварки при строительстве МЛСП «Приразломная». Автоматическая сварка. 2005. № 9. С. 37-39.

[8] Савич И.М., Рыбченков А.Г., Паньков В.И., Игнатушенко А.А., Патон В.Е., Смолярко В.Б., Бельфор М.Г., Пичак В.Г. Авторское свидетельство СССР 498131. Москва, 1976.

[9] Lebedev, V. Unique automatic arc for deep underwater welding wet process under hard limited. Cyдоходство. 2016. №2. C. 62-64.

[10] Лебедев, В. А., Гулый М. В. (2014). Быстродействующий вентильный электропривод для оборудования механизированной дуговой сварки. Мехатроника. Автоматизация. Управление, 6, 47-51.

[11] Лебедев В.А., Гедрович А.И., Бородина К.В. Электродуговая сварка плавлением металлов малой толщины. Сварка и родственные технологии - настоящее и будущее : сборник тезисов стендовых докладов Международной конференции. 2013. С. 80-81.

(C) В. А. Лебедев, Г. В. Жук, Д. М. Кражановський 